\title{
¿Dónde va la Italia del 2008?
}

\section{Francesco Occhetta SJ'}

Palabras clave: Italia, pobreza, mercado de trabajo, fútbol, crisis política.

Key words: Italy, poverty, labour market, soccer, political crisis.

Italia nace de la unificación de 1861, cuando los estados regionales de la península, junto con Cerdeña y Sicilia fueron unidos por el rey Vittorio Emanuele II. Después de un periodo de gobierno parlamentario, Benito Mussolini impuso en los primeros años 20 una dictadura fascista que duró hasta el 1945. El referéndum institucional de 2 de junio de 1946 puso fin a la monarquía de la Casa de Saboya. Los padres constitucionales aprobaron la actual constitución el 27 de diciembre de 1947 y escogieron una república parlamentaria como modelo constitucional, confiando mucha responsabilidad al parlamento y poca al gobierno. Actualmente Italia es miembro del G-8 (el grupo de los ocho grandes países industrializados) y es la séptima potencia económica mundial. Las regiones de Italia septentrional están entre las más ricas del mundo en cuanto a renta per capita. Además, la memoria del país sigue suponiendo una herencia muy exigente: Italia custodia un enorme patrimonio arqueológico, cultural y literario que ha dado vida al humanismo medieval y al Renacimiento. Todo el mundo reconoce que italianos ilustres como Maquiavelo, Dante, Leonardo o Galileo han contribuido a forjar el pensamiento político, la filosofía y las artes en Europa. Y sin embargo la idea que hay hoy de Italia en el extranjero es la de la pizza, la mafia y el mal gobierno. ¿̇Y todo esto

\footnotetext{
1 Jesuita, escritor en La Civiltà Cattolica. Los principales datos están sacados del los artículos de Michele Simona S. J. y Francesco Occhetta S.J. publicados en La Civiltà Catolica en los años 2007 y 2008. Texto final recibido en marzo de 2008. Versión castellana de Diego Alonso-Lasheras SJ.
} 
por qué? En Italia no faltan contradicciones políticas, sociales y económicas que queremos examinar en este artículo. En particular nos preguntaremos: ¿̨hacia dónde va la sociedad italiana? ¿̇uáles son las fuerzas políticas que la componen? ¿qué contribución puede hacer a Europa?

\section{La fragilidad antropológica de la sociedad italiana}

En el año 2007 los italianos han sido descritos como "vagos y pendencieros" por el Informe Censis ${ }^{2}$, rasgos con los que caracteriza las degeneraciones presentes en la sociedad italiana en la que "la desorientación, el stress de la pérdida de roles en el trabajo como en la familia produce [...] un carácter litigioso, una hiperactividad patológica que se convierte en micro-comportamiento [...]: y por ello los estadios se convierten en lugares de catarsis de una agresividad social, los muchachos en familia sustituyen el "papá, no me has comprendido" directamente por el "¿eres estúpido?" usado como estribillo despiadado de un léxico familiar del sufrimiento; las televisiones compran series de ficción cada vez más violentas [...]. Esta hiperactividad, este carácter litigioso, este oscuro gusto por lo disoluto que por lo demás se amplifica en la lucha políitca, parece encontrar la metáfora perfecta en la facilidad en el ámbito de lo privado del divorcio con el que se pasa del matrimonio para siempre al matrimonio a tiempo determinado. [...]. Crece la violencia familiar porque él o ella "no podía soportar", "no ha logrado soportar" una separación o sólo un desaire. Violencia que, contrariamente a lo que se cree, no es siempre improvisada, dictada por un impulso inmediato e incontrolado. Es, más bien, el fruto de una lenta elaboración, [...]. El gemelo de tanta sobreexcitación negativa es inevitablemente el miedo: a la enfermedad, a los inmigrantes, al terrorismo, al crimen, en resumen, a todo. Y "el miedo a todo" es claramente un síntoma patológico." ${ }^{3}$

\footnotetext{
${ }^{2}$ Cfr CensIS, $41^{\circ}$ Rapporto sulla situazione sociale del Paese 2007, Milano - Roma, FrancoAngeli Fondazione Censis, 2007.

${ }^{3}$ Ibid 70.
} 


\section{Italia}

- Forma de Gobierno: República parlamentaria

- Superficie: $301.317 \mathrm{~km}^{2}$

- Población: 58.147.733, de los cuales 3.690.052 son inmigrantes. Estimación de junio de 2007.

- Presidente de la república que "es el Jefe del Estado y representa la unidad nacional", es elegido por 7 años por el parlamento en sesión conjunta. El actual presidente es Giorgio Napoletano.

- Parlamento elegido por 5 años. Se compone de:

- Cámara de diputados: 630 diputados.

- Senado de la República: 315 senadores, más los senadores de por vida nombrados por el Presidente de la República.

- El Gobierno está constituido por el Presidente del Consejo de Ministros, nombrado por el Presidente de la República, y los ministros. El Consejo de Ministros debe obtener la confianza del Parlamento.

- Tribunal Constitucional: compuesto de 15 jueces nombrados por 9 años con la tarea de examinar la constitucionalidad de las leyes.

- El territorio está dividido en 15 regiones con un estatuto ordinario y 5 regiones con un estatuto especial.

Los italianos tienen miedo del futuro y existe el riesgo de que no miren juntos hacia la misma meta. Quizá porque ltalia sigue estando entre los países del mundo con el más alto porcentaje de ancianos: a principios de 2006 las personas con más de 65 años representaban el 19,8\% (en 1995 representaban el 16,5\%), mientras que los jóvenes con menos de 15 años representaban el 14,1 \% (respecto del $18,4 \%$ de 1995).

Este miedo obstaculiza la esperanza y los mejores cerebros huyen al extranjero. Por ejemplo el número de italianos en España ha aumentado el 400\% en 10 años. Al mismo tiempo las nuevas generaciones cargadas de licenciaturas y masteres no tienen trabajo y deben aceptar el mercado del trabajo precario, hecho de flexibilidad y falta de seguridad. 


\section{La pobreza en Italia}

En Italia hay 2.623.00 familias (es decir 7.537.00 personas que equivalen al $12,9 \%$ de la población) que se encuentran en estado de pobreza relativa y entre estos muchos son niños. Las familias que viven en condiciones de indigencia son 2.585 .00 (que representan el $11,1 \%$ ). Las regiones del sur son las más golpeadas ya que el $26 \%$ de la población está bajo el umbral de la pobreza. En estos últimos años estamos asistiendo a un fenómeno del que la sociedad italiana es poco consciente: están aumentando las familias que no se definen como pobres sólo porque sus recursos financieros superan el umbral de la pobreza por una pequeña cantidad que va de los 10 a los 50 euros mensuales. Esto núcleos familiares "en riesgo de pobreza", son alrededor de 900.000 . Estas familias, aunque tengan trabajo y una renta recurren a centros asistenciales para poder hacer frente a sus deudas. Los factores que determinan una situación de pobreza son entre otros: el elevado número de miembros de la familia, la presencia de niños pequeños, la presencia de ancianos enfermos, el bajo nivel de instrucción y la dificultad para acceder al mercado de trabajo.

Los datos hablan claro: el $26,2 \%$ de las familias con cinco o más componentes vive en condiciones de pobreza. En el Mezzogiorno (la región del sur de la península más Sicilia) este dato se eleva hasta alcanzar casi el $40 \%$. Tener tres hijos que criar significa un riesgo de pobreza del $27,8 \%$ y en el Sur este valor se eleva al $42,7 \%$. En otras palabras el nacimiento de un hijo, junto a la esperanza y la alegría, genera en la familia italiana el miedo a convertirse en una familia pobre. También la presencia de un anciano, sobre todo enfermo y atendido por la familia aumenta el riesgo de pobreza, sobre todo en las regiones del Centro y del Norte.

¡Como en España, también en Italia en mercado inmobiliario ha enloquecido! El número de familias italianas con dificultades para pagar la hipoteca o el alquiler supera los 3 millones generando duras consecuencias: sólo en Roma y Milán la ejecución de hipotecas y los embargos inmobiliarios han crecido un $16 \%$. Si además se añade el aumento de los precios de los viajes y del teléfono y todos los otros gastos fijos, los costes mensuales de una familia giran en torno a los 1.700 euros al mes. De hecho el Informe Censis afirma que la dificultad de hacer frente a gastos extraordinarios por un valor en torno a los 600 euros afecta al $40 \%$ de las familias del sur. Los sociólogos dicen que el país tiene precios alemanes con sueldos griegos.

El rostro del pobre se amplía en el imaginario colectivo. Hoy un pobre en la sociedad italiana puede vestir chaqueta y corbata y ser el vecino de casa, puede tener 
un buen móvil y cobrar una pensión. Dada la apariencia que impone la sociedad de consumo, ninguno podría darse cuenta que no llega a fin de mes. Muchas familias italianas pueden encontrarse en la pobreza de manera imprevista por una enfermedad grave de un familiar, por la precariedad del trabajo o a causa de los gastos financieros cada vez mayores.

El tema conlleva implícitamente también la necesidad de madurar un mejor modo de actuar y organizar la ayuda a los nuevos pobres. Desgraciadamente no faltan en nuestras ciudades personas que mendigan y que viven bajo el control de mafias rumanas, albanesas o marroquíes.

Reducir la pobreza con políticas de choque que crean cohesión social, sobre todo en el sur de Italia, significa alejar de un destino de marginalidad a tantos muchachos y niños que han tenido la mala suerte de nacer en el barrio equivocado; hacer frente en muchas regiones del Sur al predominio de una economía criminal que encuentra en la pobreza de algunas zonas la posibilidad de disponer de un "ejercito de reserva" para el propio mercado de trabajo.

\section{El problema del trabajo}

Italia tiene una densidad de población entre las más altas de Europa pero con una distribución irregular en el territorio. Entre 1960 y 1990 más de 6 millones de personas se han visto forzadas a abandonar las regiones pobres del Sur, la zona montañosa del norte y muchos pueblos del noreste para ir a vivir a Turín, Milán y Roma. Las dos primeras ciudades viven de la industria, la capital, por el contrario, de estructuras ligadas al gobierno y a la Iglesia. En Roma viven alrededor de 30.000 personas de todo el mundo entre seminaristas, sacerdotes, religiosos, religiosas, etc.

En el norte el desempleo es menor gracias a las grandes empresas del noroeste, cuya capital económica es Milán, y a las pequeñas y medianas empresas del noreste. La diferencia de nivel social entre el norte y el sur es cada vez más dramático, tanto que en la protesta de las zonas más ricas ha sido aprovechada por la Liga Norte que con su lema "Roma ladrona" quiere que los impuestos del norte se queden en el norte.

En 2004120.000 personas del sur se han mudado al Centro-Norte, mientras que alrededor de 60.000 han recorrido el camino contrario, con un saldo de 60.000 
a favor del Centro-Norte. Se estima también que los desplazamientos temporales rondan los 150.000 hacia el Centro-Norte. En 2006 el número de personas que buscan empleo ha bajado del millón (907.000), con una reducción en términos absolutos, respecto a $2000^{4}$ de más de 500.000 personas. El desempleo en el sur en los últimos seis años se ha reducido más de un tercio (-37\%). Por eso la tasa de desempleo ha pasado del $19 \%$ al $12,3 \%$ del año pasado, un valor no muy lejano de la media de la Unión Europea (8\%).

Ante estos datos se plantea una pregunta: $\dot{\text { se }}$ debe el éxito a la reforma del sistema laboral aprobada en 2003? Los economistas se encuentran divididos al respecto. Para algunos estudiosos de izquierda los trabajadores "flexibles" se encuentran colocados en posición de desventaja: la discontinuidad de su carrera profesional junto al bajo nivel de sus contribuciones al sistema de la seguridad social aumenta la dificultad del trabajador de conseguir el derecho a una pensión para afrontar la vejez.

Por el contrario, los que favorecen la reforma sostienen que los contratos flexibles tienen tres funciones: dan más transparencia al mercado; facilitan la transición del desempleo al empleo; y atenúan las fases coyunturales difíciles y reducen el riesgo de desempleo del trabajador.

El competitivo escenario internacional es el que ha impuesto esta decisión en Italia. En los últimos decenios el mundo del trabajo italiano ha tenido que irse conformando a las nuevas exigencias de los mercados en los que la legitima aspiración de estabilidad de los trabajadores debe conjugarse con la también legitima necesidad de flexibilidad de las empresas. El verdadero problema estriba "en un sensible y constante aumento de las desigualdades de productividad entre los trabajadores, que se traduce en una creciente desigualdad entre ellos." ${ }^{5}$ Pero aun hay más. El actual contexto competitivo se caracteriza por ciclos económicos cada vez más breves, por mercados que crecen menos y cuya evolución es menos previsible: en cada cambio hay trabajadores que son capaces de adaptarse y otros que por no ser capaces se quedan atrás. El trabajador italiano, acostumbrado al trabajo seguro no consigue adaptarse. En otras palabras, la competición cada vez más global en el mundo del trabajo está alcanzando niveles cada vez más preocupantes que llevan a preguntarse: żqué pasa con quien no puede? El centro de la cuestión no es la flexibilidad del trabajo que favorece la ley, sino más bien el fenómeno de una

\footnotetext{
${ }^{4}$ Cfr Rapporto Svimez 2007 sull'economia del Mezzogiorno, Bolonia, il Mulino, 2007, 125.

${ }^{5}$ P. ICHINO (2007), "Come si combatte la precarietà", en Corriere della Sera, 20 de agosto, 1 y 31.
} 
negativa precariedad generada por el abuso de la reforma por parte de muchas empresas italianas. El problema es esencialmente de naturaleza ética e implica la responsabilidad social de las empresas; es decir en una correcta aplicación de las leyes a favor de toda la colectividad.

Tras un decenio, las reformas introducidas han dado a ltalia una situación normativa de mayor semejanza a la de los países europeos de mayor tamaño. Pero esto no basta. En el tramo de edad entre los 25-30 años del resto de Europa están ocupados el $75 \%$ de los jóvenes frente al $66 \%$ de ltalia, mientras que la renta media de los jóvenes italianos es casi la mitad de sus coetáneos ingleses y es un $50 \%$ más bajo que el de los franceses o alemanes.

Para modernizar el país es urgente que la reforma del mercado de trabajo venga acompañada de la del estado del bienestar, con una adecuada serie de "amortiguadores" sociales . Los países como Dinamarca donde hay libertad de despido -y justamente por eso las empresas contratan sin problema y la tasa de desempleo es baja-son también aquellos en los que las prestaciones por desempleo son más generosas. Si se quiere modernizar el país se puede hacer, pero es necesario un cambio de mentalidad.

\section{Los inmigrantes}

Los inmigrantes regularizados en Italia pasaron de los 2.786 .340 de 2004 a los 3.690.052 de 2006. Provienen de Europa 49,6\%, de África 22,3\%, de Asia 18,0\%, de América $9,7 \%$ y de Oceanía, junto con los apátridas y los de procedencia desconocida, 0,4\%. La mayoría trabaja en el sector de los servicios $(53,6 \%)$, mientras que el $35 \%$ trabaja en la industria y el 6,4\% en la agricultura y la pesca. "De los países industrializados, Italia se coloca entre los primeros países de Europa y del mundo en cuanto a ritmo de crecimiento del número de inmigrantes. Si en el bienio 2007-2008 los flujos continúan con la misma fuerza de los últimos dos años, los cambios serán notables: (...); en este momento no se trata sólo de decidir cuáles deban de ser los mecanismos de ingreso, la estancia, el mercado de trabajo, sino de pactar objetivos válidos para una sociedad intercultural y multiétnica." ${ }^{6}$ Continúa siendo significativo pero difícil de cuantificar con precisión el número de inmigrantes irregulares. Un indicador parcial lo sitúa entre 300.000 y 400.000 .

${ }^{6}$ Cfr CARITAS (2007), Migrantes, Immigrazione. Dossier Statistico 2007. XVII Rapporto, Roma, Idos, p.13. 
Es necesaria una nueva ley de inmigración que regule de manera más racional el fenómeno migratorio que es de carácter estructural, ley que debe tener en cuenta el largo plazo.

Hay que reconocer que la economía del país avanza gracias a los inmigrantes que realizan los trabajos que en general no quieren hacer los italianos. Hace unas semanas un periódico decía que hay muchas pizzerías del norte de ltalia que no consiguen encontrar pizzeros italianos, faltan también albañiles, obreros de la industria pesada, mientras que quienes cuidan a los ancianos y a los niños son casi todos inmigrantes.

\section{Las infraestructuras}

A diferencia de España cuando se viaja en coche por Italia sólo se ven casas. Para construir la conexión ferroviaria de alta velocidad entre Turín y Lyon (la llamada TAV) ha sido necesario derruir edificios enteros por la falta de espacio en el territorio italiano. A pesar de este esfuerzo, la insuficiencia de la red viaria y ferroviaria es, después del excesivo peso de la burocracia, el elemento que más desincentiva la inversión productiva. "En muchas provincias el tráfico está tan congestionado que la circulación por carretera sufre un retraso medio superior al $50 \%$ de lo que llevaría en circunstancias normales". Es el caso de Roma, Nápoles, Génova o Bolonia.

Para recorrer $100.000 \mathrm{~km}$ al año en Italia hacen falta una media de 2.000 horas frente a las 1.818 de Francia o Alemania. El costo del kilómetro de transporte por carretera es de 1,451 euros, más alto no sólo que en los países de Europa oriental, sino que en países como Francia (1,340 euros), Alemania ( 1,289 euros) o España $(1,078$ euros). En los últimos años se ha empezado a volver a invertir en el sector de manera significativa y esta decisión muestra el vínculo entre la "riqueza que generan las diversas regiones y la red viaria y ferroviaria de que disponen, es decir, allá donde se produce la tasa más alta de valor añadido del país se dispone de la más tupida trama de infraestructura y centros logísticos. ${ }^{\text {7 }}$

${ }^{7}$ Cfr CENSIS (2007), $41^{\circ}$ Rapporto sulla situazione sociale del Paese 2007, Milán-Roma, FrancoAngeli - Fondazione Censis, p. 475. 


\section{El deporte nacional y sus valores: el fútbol}

En junio de 2006 Italia ganó los mundiales de fútbol mientras los tribunales investigaban la corrupción en el fútbol profesional que es la causa de una cultura que impone contravalores: comportamiento desleal, intentos de corrupción, la habilidad para engañar. La venta de los derechos de televisión en el verano de 2003 puso en duda la marcha del campeonato, mientras crece el maridaje entre fútbol y política. Comprar un equipo de fútbol significa el trampolín a la propia visibilidad, donde la propia historia va ligada al resultado del equipo.

En Italia hay 1.521 .865 jugadores de fútbol pertenecientes a 54.473 equipos en la superficie de unos campos que equivalen a $76.620 \mathrm{~km}^{2}$ disputan 700.000 partidos al año. Se calcula que las personas cercanas al mundo del fútbol sean 23.500.000, mientras que los hinchas rondan los 32.000.000..$^{8}$ Cada domingo para controlar los desmanes son necesarios 11.000 miembros de las fuerzas del orden. Pero el esfuerzo del estado en términos de seguridad y gasto no es suficiente. Si la violencia es la respuesta a las consecuencias de la estructura social, expresión de una crisis de sentido y prueba de la búsqueda de identidad y de la pérdida de perspectivas, y del empobrecimiento de los vínculos sociales y familiares, la cuestión de la responsabilidad atañe a toda la sociedad y debe ser afrontada en primer lugar. El fútbol profesional es un detonante social en el que encuentra desahogo la violencia social.

Que los 700.000 muchachos de los 6 a los 16 años que juegan al fútbol, de los que sólo el $0,2 \%$ accederá a la serie $A$, vivan el deporte como escuela de valores es una necesidad de la que toda la sociedad se beneficiaría si fuera atendida. Para poder volver al fútbol como escuela de valores capaz de formar a los jóvenes se está experimentando con muy buenos proyectos en las escuelas. Pero hay más. Sigue existiendo una urgencia por crear una autoridad europea que prevea un registro para los jugadores profesionales y establezca un límite a los sueldos, fijando un máximo y un mínimo.

En Italia es necesario educar en valores en el deporte nacional que es el fútbol para encauzar la crisis moral de la política. Los responsables del fútbol deben elegir entre los valores en conflicto: la dimensión de encuentro y de la gratuidad frente a los intereses del patrocinador que reclama los frutos de su inversión. Si se recupera el valor lúdico del fútbol, el encontrarse para crecer en amistad, el

${ }^{8}$ Eurisko da las siguientes cifras aproximadas: Juventus, 9.777.800; Milan, 5.004.000; Inter, 4.731.372; Roma, 1.991.180; Lazio, 813.000; Torino, 669.500. 
compartir como capacidad de abrirse al otro y sentirse reconocido como persona, el sentido del sacrificio como algo necesario para alcanzar un objetivo... también la democracia saldrá beneficiada.

\section{La política italiana}

El 24 de enero cayó el gobierno Prodi. Se votará el 13 y el 14 de abril. El panorama político es aun más complejo que el español. En la última legislatura, la del gobierno Prodi, los partidos con representación parlamentaria eran 23. El exceso de poder de estos ha bloqueado las reformas que el país necesita. Los partidos no gozan de la confianza de la gente, se han convertido en estructuras de gestión del poder. Los partidos y el país real aparecen como separados pero viviendo en la misma casa. El gobierno Prodi, un gobierno de centro izquierda en el que han convivido un espíritu católico y uno laico, ha sido uno de los pocos que ha sabido arreglar la economía: el PIB ha crecido un $2 \%$ y han crecido los ingresos fiscales, pero no ha sabido encontrar un acuerdo a propósito de las uniones de hecho y de la liberalización de algunas normativas.

Una de las razones de la crisis política actual es la ley electoral a propósito de la cual no se consigue llegar a un acuerdo. El actual sistema electoral se regula por la ley 270 de 21 de diciembre de 2005 que aprobó el centro derecha. La ley atribuye un premio de mayoría a la coalición que vence si no alcanza los 340 escaños. Con este nuevo sistema de voto el elector no puede expresar preferencia ninguna por un candidato. En la papeleta de voto sólo se puede marcar una cruz sobre el símbolo del partido o de la coalición, porque las candidaturas las deciden las secretarías de los partidos que establecen el orden en las listas y como consecuencia la elección de cada candidato. El sistema proporcional de la Cámara se ha demostrado incompatible con el sistema mayoritario del Senado previsto en la Constitución.

Esta misma preocupación la ha expresado la Conferencia Episcopal Italiana (CEI) que ha subrayado la necesidad de que el próximo Parlamento modifique la ley electoral "volviendo a dar al ciudadano la posibilidad de elegir sus representantes". El actual sistema electoral, ha explicado el Secretario General de la CEI, Monseñor Giuseppe Betori, obliga a los electores católicos a un mayor discernimiento ya que no pueden elegir directamente quién saldrá elegido. A diferencia de la Nota de los obispos españoles durante la campaña electoral que se ha prestado a muchos malentendidos, los obispos italianos han subrayado que no quieren inclinarse ha- 
cia ningún partido político, pero piden "a los electores católicos, a los candidatos católicos y a los futuros elegidos que se atengan a los valores de la "defensa de la vida" y a la tutela de la familia tradicional."

Si el voto con frecuencia se orienta por "la urgencia de lo cotidiano", para los creyentes "las urgencias se deben proyectar en el horizonte de los grandes valores". Las prioridades: mafia, usura, accidentes de trabajo, escuela, familias y otras cuestiones de las que los programas políticos hablan muy poco, son sin embargo las principales entre las preocupaciones de la Iglesia. Además de la mafia, son verdaderas "plagas", una usura desbordada y los accidentes de trabajo. Los obispos italianos están "muy preocupados" de la ausencia en el debate preelectoral de temas decisivos como la "formación, en la escuela pero también en la familia."

En lo que toca a los católicos, como buenos ciudadanos deben sobre todo considerar cuál es la situación del país y la situación institucional para después valorar las posiciones de los partidos en temas con repercusiones éticas. Su voto tendrá que ir a aquellos partidos que en el Parlamento defiendan lo más posible la visión moral católica, y después sobre la moral fundada en la recta razón y que favorece el bien común del país. Con todo también en el nuevo parlamento cuando se llegue a la discusión de temas con ramificaciones éticas será necesario un acuerdo "transversal" de los parlamentarios católicos y de aquellos de buena voluntad que militan en diversas formaciones políticas.

En algunas partes de ltalia el crimen organizado es tan fuerte como el estado hasta el punto de condicionar la política. Valga como ejemplo las 250.000 toneladas de deshechos abandonados en las calles de Nápoles y de la región de Campania, de las cuales ha hablado la prensa de todo el mundo. Es un ejemplo del desgobierno y de la injerencia del crimen organizado en el sur del país. Ya se tomó la decisión política correcta hace doce años cuando se aprobaron centrales térmicas que eliminaran las basuras y produjeran energía. Sin embargo, las centrales térmicas nunca fueron construidas y los vertederos no se han clausurado en parte porque están controlados por las organizaciones mafiosas.

No faltan sin embargo en estos últimos meses signos de novedad y de esperanza. El elemento de novedad de cara a las próximas elecciones lo constituye la decisión del Partido Democrático de presentarse en solitario a las elecciones, disolviendo la coalición de la Unión que lo hacía aliado de los partidos de izquierda (Refundación Comunista, Izquierda Democrática, Comunistas Italianos y los Verdes), los cuales a su vez se presentan a las elecciones en la lista unitaria llamada Izquierda Arco iris. En un cierto sentido, el nacimiento del Partido Democrático y la decisión de 
presentarse con programa propio ha "obligado" al centro derecha a formar una lista unitaria - por ahora no un partido, como han hecho los Demócratas de Izquierdas y la Margarita que se han fusionado en el Partido Democrático-, el Pueblo de las Libertades. En él se encuentran presentes Forza Italia de Silvio Berlusconi, Alianza Nacional de Gian Franco Fini y un número aun impreciso de pequeños partidos. Esta lista se presenta en coalición con la Liga Norte de Humberto Bossi que quiere la autodeterminación del Norte. ${ }^{9}$ Acudirá también a las elecciones un partido de centro, la Unión Demócrata Cristiana de Pierferdinando Casini que podría recibir muchos votos y también concurre una lista por el "no al aborto" de Giuliano Ferrara conocido periodista italiano.

Creemos que este puzzle es la etapa que precede a un sistema de alternancia de partidos. El juego de las alianzas entre los partidos es débil. De hecho el análisis del voto revela que muchos de los clásicos obreros de izquierda votan a Berlusconi, mientras que una parte de los empresarios propietarios de medianas empresas votan a la izquierda.

Por primera vez desde la guerra se asiste en Italia a un alejamiento entre los políticos laicos y los católicos que en Italia, en los momentos de crisis han compartido proyectos y valores comunes.

Los católicos demócratas parecen perder identidad en el centro izquierda con la alianza que ha hecho Veltroni con los radicales. Los católicos liberales de centro derecha son con frecuencia instrumentalizados en temas como la familia, la educación o la defensa de la vida. Los católicos en política, después de casi medio siglo de partido único en la Democracia Cristiana, disuelto en 2003, buscan ahora su identidad.

Parece que en Italia se esté introduciendo el pensamiento laicista característico de España que pretende, por primera vez en la historia italiana, fundar la libertad religiosa sobre el principio de la laicidad, imposición totalmente desprovista de fundamento. Más bien se debería tratar de lo contrario. Lo que funda y estructura la laicidad es el principio de la libertad. En otras palabras, es la garantía del derecho fundamental de la libertad religiosa en todas sus dimensiones, incluso

\footnotetext{
9 El Polo de la Libertad prevé unos costes que oscilan entre los 72 y los 87.000 millones de euros y unos ingresos de 33.000 millones; mientras que el programa del Partido Democrático prevé costes que oscilan entre los 19 y los 28.000 millones de euros y unos ingresos de 18.000 millones. Pero un elemento significativo lo constituye el enfrentamiento con todo lo que el centro derecha y el centro izquiera han hecho en los años en que permanecieron en el gobierno, más allá de las actuales promesas, condicionadas -por otro lado- por un año 2008 probablemente difícil desde el punto de vista económico.
} 
la institucional, lo que constituye la condición de cara a una convivencia social pacífica y una correcta laicidad. Este intento, sin embargo, quiere denunciar el Concordato de 1984 entre el Estado y la Iglesia católica que viene regulado por la Constitución.

Con Alcide De Gasperi ltalia fue de los primeros países en creer en la Europa unida. Fue una intuición profética. Así como permanecen como un punto final los valores recogidos en los primeros 10 artículos de la Constitución italiana como ejemplo del encuentro entre el pensamiento católico, laico y comunista. El gobierno de los ayuntamientos y de las regiones está resultando beneficioso, pero existe el riesgo de que se desintegre la unidad nacional y se favorezcan los intereses locales. La mayoría de la ciudades están bien administradas y son vivibles, y confirma que Italia es "el país de las 100 ciudades."

Durante el gobierno Prodi, así como durante su presidencia de la Comisión europea, Italia ha contribuido en gran medida a la construcción de Europa a partir de la moneda única y de la Constitución europea. Prodi ha señalado los siguientes retos que son para Italia una prioridad en Europa: África, Oriente Medio, la pena de muerte y los derechos humanos, la lucha contra la pobreza y el trabajo por la paz, el medio ambiente, el clima y la familia. El papel de Italia en Europa sigue siendo importante, sea por su situación geográfica cerca de los países del sur y del Mediterráneo, sea por su amistad con EEUU. La integración que está viviendo el propio país es la línea política que está promoviendo en Europa. Italia cree que sólo si Europa vence en los retos regionales podrá hacer escuchar su voz en el mundo. Una prioridad para ltalia es promover el multiculturalismo y la cohesión a pesar de la dura prueba de Kosovo. Aunque de Lisboa ha salido un acuerdo modesto y la Constitución europea no se ha atrevido a mucho, Italia quiere construir una Europa que no sea sólo una suma de estados, sino la casa común de casi 500 millones de personas.

Las urgencias que hay que afrontar son aquellas internas. En el periodo post-ideológico hecho de ideas fuertes y proyectos globales, la democracia italiana necesita elaborar una cultura de los medios, es decir, de reflexionar sobre los instrumentos cuya ausencia hace que los fines mismos de la democracia se transformen en un espejismo. El punto primero y fundamental es que Italia necesita como país revisar su propia historia y los valores que la fundan. Además es importante ayudar a las minorías que "tiran del país", como algunas grandes empresas nacionales, el sector del voluntariado, el turismo y la cultura, que crecen en calidad y competitividad. 
Es urgente repensar el sector público que está sobredimensionado, los casos en los que los servicios públicos y de las infraestructuras resultan inadecuados, y la discriminación en el acceso a los servicios públicos como los hospitales y los ministerios que pueden acabar frenando el crecimiento o convirtiendo en oligarquía el poder que gestionan los partidos.

En resumen, una política que se reapropie de su papel, que descubra la más importante de sus funciones: la de dirigir y a la vez la de servir a la sociedad y al bien común. Pero para hacer esto no cabe perder tiempo. Cada italiano está llamado a aportar su propia contribución responsable y consciente. El destino de paz y de libertad de las generaciones futuras está en juego. 